\title{
Prevalence of Obesity in Women of Accra, Ghana
}

\begin{abstract}
Rosemary B. Duda ${ }^{1}$, Rudolph Darko ${ }^{2}$, Joseph Seffah ${ }^{3}$, Richard M.K. Adanu ${ }^{3}$, John K. Anarfi ${ }^{4}$, Allan G. Hill ${ }^{5}$
1. Department of Surgery, Beth Israel Deaconess Medical Center, Harvard, Medical School, 330 Brookline Avenue, Boston MA 02215 USA; Telephone:617-667-2169;Facsimile:617-667-2978;e-mail: rduda@caregroup.harvard.edu; 2. Department of Surgery, Korle Bu Teaching Hospital, University of Ghana, Accra, Ghana. e-mail: rdarko@ug.edu.gh; 3. Department of Obstetrics and Gyneacology, Korle Bu Teaching Hospital, University of Ghana, Accra, Ghana;e-mail: jseffah@yahoo.co.uk, e-mail:rmadanu@yahoo.com; 4. Institutefor Statistical, Social and Economic Research, University of Ghana, Accra, Ghana. e-mail: jkanarfi@isser.ug.edu.gh; 5. Department of Population and International Health, Harvard School of Public Health, 677 Huntington Avenue, Boston, MA. 02115 USA. Telephone: 617-495-3007;Facsimile: 617-495-5418;e-mail:ahill@hsph.harvard.edu
\end{abstract}

*Corresponding Author: Rosemary B. Duda

\section{SUMMARY}

The Women's Health Study of Accra, Ghana measured the burden of obesity and obesitylinked illnesses in urban women. This is a Cross-sectional community based study. 1328 adult women, age 18 years and older, were selected as a representative sampling of the women of Accra. A comprehensive medical history, physical examination and laboratory tests were performed. Overweight and obesity status was determined by calculating the body mass index (BMI) $\left(\mathrm{kg} / \mathrm{m}^{2}\right)$. BMI measurements are available for 1237 non-pregnant women. A total of 430 women $(34.8 \%)$ were obese; $340(27.4 \%)$ were overweight; $369(29.8 \%)$ were normal weight; and $98(8.0 \%)$ were underweight. Risk factors for obesity include age 50 to 70 years, OR $2.12[1.72-2.62], p<0.001$; total pregnancies $>5(p<0.001)$; mean age of last delivery $>34$ years $(p<0.001)$; ownership of a television OR $1.57[1.20-2.07], p=0.001$; telephone OR $1.55[1.22-1.98], p=0.001$; or a refrigerator OR $1.55[1.20-2.00], p=0.001$. There was no significant association with socioeconomic status. Significant medical conditions associated with obesity include hypertension OR 2.97 CI [2.17-4.05], p<0.001; elevated fasting blood glucose OR 1.94 [CI 1.04 - 3.62], $p=0.037$. This study identifies an unexpected high prevalence of obesity and obesity-linked illnesses in this population. Public and professional awareness of the prevalence of obesity and the associated health risks are critical for programs designed to improve women's health.

[Afr J Health Sci. 2007; 14:154-159]

\section{Introduction}

The prevalence of obesity is a worldwide public health concern. Contrary to conventional wisdom, the epidemic is present in developed industrialized countries and in developing countries. It is estimated that over 115 million people suffer from obesity related health conditions in the developing nations. $[1,2,3]$

The Women's Health Study of Accra (WHSA) was conducted in 2003. It was a population-based survey assessing the burden of communicable and non-communicable diseases in adult women residing in the urban environment of Accra, Ghana. One component of the survey was designed to provide an objective measurement of obesity, to assess determinants of obesity and to compare the health of obese women with normal weight women in the study.

\section{Methods}

The area chosen for this study was the administrative unit known as the Accra Metropolitan Area, the core urban area within a larger region known as Greater Accra. The metropolitan area contains 1.66 million people and 373,540 households, according to the March 2000 census of Accra [4]. To ensure that this cohort represented all women aged 18 and older in the city, an extensive program of mapping and listing of eligible households was performed prior to the HHS interviews. The 2000 Population and Housing Census provided a full enumeration of the population of Accra on census night, 26 March 2000.

A representative sample of 1328 Ghanaian women, age 18 years and older, who resided in Accra were selected for study participation by a two-stage cluster probability sample stratified by socioeconomic status based on the 2000 Ghanaian census data and included all ethnicities and religions [5]. 
These 1328 women participated in both a household survey (HHS) for self-reported overall health and a comprehensive medical and laboratory examination (CMLE) and are a sampling of a larger cohort of 3183 women who were participating in the HHS only. The age groups used for the overall study sampling were 18-24 years, 25-34 years, 35-54 years and 55 to 100 years. The response rate for participating in the CMLE after the HHS was 99\%. No financial incentives were provided to the women.

The CMLE was performed at Korle Bu Teaching Hospital, Accra, Ghana. It included a complete medical history of past illnesses, review of systems, family history, medication history, complete physical examination, anthropometric measurements [6], Papanicolaou smear, full blood count, fasting blood glucose, lipid panel and HIV testing. Study participants were individually counseled for participation in the study and informed consent was obtained by signature or thumbprint.

Body mass index (BMI) was defined as BMI $\leq$ 18.5 underweight; BMI 18.5 - 24.9 normal weight; BMI 25.0 - 29.9 overweight; and $\geq 30.0$ obese [7]. Morbid obesity is defined as $\mathrm{BMI} \geq 40.0$. Unless specifically stated, obese weight category refers to all those with a $\mathrm{BMI} \geq 30.0 \mathrm{~kg} / \mathrm{m}^{2}$.

The data were coded and entered into the EPI6 database at the Institute for Statistical, Social and Economic Research (ISSER), University of Ghana. Statistical analyses were performed using SPSS version 13.0 for Windows (SPSS, Inc., Chicago, IL.). Statistical analysis was performed using descriptive frequencies, binary logistics regression analysis, Student t-Test and non-parametric analyses including Wilcoxan Rank Sum Test, Fisher's Exact Test and Chi-square analysis. The Odds Ratio (OR) with a 95\% confidence interval (CI) was used to describe the strength of the association.
The Institutional Review Boards at the Harvard School of Public Health and Noguchi Memorial Institute for Medical Research, University of Ghana approved this study. The Committee on Clinical Investigations, Beth Israel Deaconess Medical Center, approved data analysis.

\section{Results}

\section{Measure of Obesity}

There were 39 women that were identified as pregnant by either history or physical examination and were excluded from the analysis. Women who were confined to wheelchairs and/or otherwise unable to step on the scale were not weighed. A total of 1237 women had both a height and weight measurement obtained and BMI calculated. The mean age was $47.2 \pm 18.0$ years (range 18 to 100 years). The mean BMI was $27.9 \pm 7.2 \mathrm{~kg} / \mathrm{m}^{2}$ (range $12.0-61.1 \mathrm{~kg} / \mathrm{m}^{2}$ ).

The results of the BMI compared to age by decade are provided in Table 1. A total of 430 women $(34.7 \%)$ were obese and 340 women were overweight $(27.6 \%)$. Included in the obese category are 75 women $(6.1 \%)$ who were identified to be morbidly obese (BMI $\geq 40.00 \mathrm{~kg} / \mathrm{m}^{2}$ ).

From those who answered the question on the HHS, 42/1206 (3.5\%) of those who self-reported obesity had an objective BMI assessment. Of that group, $38(90.5 \%)$ had a BMI $\geq 30.0 ; 3(7.1 \%)$ had a BMI in the overweight category and $1(2.4 \%)$ was normal weight. Of the 1164 non-pregnant women who perceived their weight to be other than obese, $383(32.9 \%)$ were obese, $329(28.3 \%)$ were overweight, $358(30.8 \%)$ were normal weight and 94 $(8.1 \%)$ were underweight. There was no association of self-perception of obesity with age.

Table 1. Body Mass Index $\left(\mathrm{kg} / \mathrm{m}^{2}\right)$ compared to Age Group by Decade

\begin{tabular}{|c|c|c|c|c|c|c|c|c|c|c|}
\hline \multirow[t]{3}{*}{ Age } & \multicolumn{10}{|c|}{ Body Mass Index } \\
\hline & \multicolumn{2}{|c|}{$<18.5$} & \multicolumn{2}{|c|}{$18.5-24.9$} & \multicolumn{2}{|c|}{$25.0-29.9$} & \multicolumn{2}{|c|}{$\geq \mathbf{3 0 . 0}$} & \multicolumn{2}{|c|}{ Total } \\
\hline & $n$ & $\%$ & $n$ & $\%$ & $n$ & $\%$ & $n$ & $\%$ & $n$ & $\%$ \\
\hline 18-29 & 43 & 15.8 & 128 & 47.1 & 68 & 25.0 & 33 & 12.1 & 272 & \\
\hline 30-39 & 9 & 5.6 & 43 & 26.5 & 37 & 22.8 & 82 & 45.1 & 162 & \\
\hline $40-49$ & 13 & 5.4 & 53 & 21.9 & 82 & 33.9 & 94 & 38.8 & 242 & \\
\hline $50-59$ & 9 & 4.1 & 55 & 25.2 & 58 & 26.6 & 96 & 44.0 & 218 & \\
\hline 60-69 & 8 & 4.1 & 46 & 23.5 & 52 & 26.5 & 90 & 45.9 & 196 & \\
\hline $70+$ & 16 & 10.9 & 44 & 29.9 & 44 & 29.9 & 43 & 29.3 & 147 & \\
\hline Total & 98 & 7.9 & 369 & 29.8 & 341 & 27.6 & 429 & 34.7 & 1237 & 100 \\
\hline
\end{tabular}

\section{Risk Factors for Obesity Age}


BMI was significantly associated with increasing age $(p<0.001)$ until the eighth decade. The odds ratio of being obese and age 50 to 69 was 2.12 [1.72-2.62], $\mathrm{p}<0.001$ compared to women under age 50 . Obesity continues to increase after age 50 until the seventh decade where the prevalence of obesity reaches a high of $45.9 \%$. The prevalence of obese women decreases with age after age 70 years. Obesity was identified in $29.3 \%$ of all women aged 70 years and greater, the second lowest prevalence age group in this study.

\section{Reproductive History}

The analysis was performed only for parous women $(n=1142)$. There was a positive association for select reproductive health factors as a risk for obesity. The mean number and standard deviation of reported full term pregnancies are as follows and are compared to normal weight women for analysis: 4.14 \pm 3.07 ( $\mathrm{p}=\mathrm{NS}$ ) underweight women; $4.68 \pm 3.44$ normal weight; $5.64 \pm 3.09(\mathrm{p}<0.001)$ overweight; $5.70 \pm$ $2.99(\mathrm{p}<0.001)$ obese; and $6.75 \pm 2.86(\mathrm{p}<0.001)$ morbidly obese women.

The mean age at last delivery was significantly associated with BMI when compared to normal weight women. The mean age in years of last delivery was $30.1 \pm 7.1 \quad(\mathrm{p}=0.016)$ underweight women; $32.7 \pm 7.5$ normal weight; $34.4 \pm 7.1 \quad(p<0.001)$ overweight; and $33.7 \pm 6.6 \quad(p=0.007)$ for obese women. There was no association with mean age at first delivery and BMI. The mean age of the first delivery was 21.6+3.6 for underweight women; $21.8 \pm 4.3$ for normal weight women; $22.0 \pm 4.2$ for overweight women; $21.4 \pm 4.0$ for obese women.

\section{Leisure-time and work activity}

The majority of women in this study in general are sedentary. Few participate in moderate to vigorous work or leisure time activities. A total of 906/1060 $(85.5 \%)$ reported a sedentary lifestyle with no difference whether the women were obese $(84.3 \%)$ or non-obese $(87.6 \%), \mathrm{p}=\mathrm{ns}$.

\section{Conveniences}

Obese women were significantly more likely than non-obese women to own a television (333/426 vs. 554/798, OR 1.57 [1.20-2.07], $\mathrm{p}=0.001$; a refrigerator (309/426 vs. 503/798, OR 1.55 [1.20-2.00], p=0.001); a telephone (167/426 vs. $234 / 797$, OR 1.55 [1.22$1.98], \mathrm{p}<0.001)$ or a car $(56 / 352$ vs. $37 / 362$, OR 1.40 [1.01-1.98], $\mathrm{p}=0.043$.

\section{Socio-economic factors}

There was no significant overall association with obesity and socio-economic factors including level of education obtained, marital status, ethnicity, work status, occupation, hours of paid employment, number of household members, monthly income, or sub-metropolitan area of residence.

\section{Diet}

The women were questioned about their diet, cooking oil and consumption of fruit and vegetables. 96.2\% of women reported preparing all meals at home, including women who work outside the home. Meals are relatively standard with a starch base and may include meat or fish. Only 12 women $(1.0 \%)$ women reported never using any type of cooking oil or fat when preparing meals, 6 were obese, three overweight and three normal weight. The most frequent cooking oil is palm oil $(57.9 \%$ overall), followed by a refined oil called Frytol® $(34.8 \%$ overall). There was no association with use or type of cooking oils and obesity. Fruit consumption at least once a week was reported by 1029/1263 (81.5\%) Vegetable consumption was more frequently reported with $1170 / 1217(96.1 \%)$ of women consuming vegetables at least once per week. Less than $1 \%$ of all of the women eat one serving of fruit and vegetables per day. There was no association with fruit or vegetable consumption and obesity.

\section{Medical conditions associated with obesity}

Women with a BMI $\geq 30$ were significantly more likely $(\mathrm{p}<0.001)$ than all other women to have been hospitalized for an illness and to have previously been diagnosed with hypertension or diabetes. Obese women were also significantly more likely $(\mathrm{p}<0.001)$ to report difficulty walking, shortness of breath with exertion, chest pain with exertion and chest palpitations. Obese women were no more likely than non-obese women to report arthritic joint pain, chest pain at rest, asthma or chronic lung disease symptoms, stroke, or myocardial infarction,

Hypertension was defined as an elevated blood pressure with a systolic reading $\geq 140 \mathrm{mmHg}$. Table 2 shows the comparison of BMI category with those who had a hypertensive blood pressure reading. Hypertension as a univariate variable was significantly associated with age $\geq 50$ years, $p<0.001$. In a multivariate analysis, obese women were almost three times as likely to be hypertensive as non-obese women, OR 2.97 CI [2.17-4.05], p<0.001. A morbidly obese woman was almost seven times as likely as a woman of normal weight to be hypertensive OR 6.94 [CI 3.27 - 14.72], p $<0.001$. Compared to normal weight women, obese women were approximately twice as likely to experience chest pain with exertion OR 2.17 [1.43-3.32], $\mathrm{p}=0.001$ and shortness of breath on exertion OR 2.19 [1.56-3.08], $\mathrm{p}<0.001$. 
Table 2: Overall Prevalence of Hypertension Compared to BMI.

\begin{tabular}{|l|l|l|l|}
\hline BMI $\left(\mathrm{kg} / \mathbf{m}^{2}\right)$ & \multicolumn{2}{|l|}{ Elevated Systolic BP } & Total \\
& $\mathbf{1 4 0} \mathrm{mm} \mathrm{Hg}$ & \\
\hline & n & \% & \\
\hline$<18.5$ & 31 & 31.3 & 99 \\
\hline $18.5-24.9$ & 134 & 35.3 & 380 \\
\hline $25.0-29.9$ & 166 & 47.2 & 352 \\
\hline$\geq 30.0$ & 286 & 65.1 & 439 \\
\hline Total & 617 & 48.6 & 1270 \\
\hline
\end{tabular}

\section{Results of laboratory tests \\ Fasting blood glucose}

The overall prevalence rate of an elevated FBG $(\geq$ $6.5 \mathrm{mg} / \mathrm{dl}$ ), a marker for adult onset type 2 diabetes, was $8.3 \%$ (98/1186). The prevalence rate of the elevated FBG increased with increasing BMI. This study found that $16(4.5 \%)$ had an elevated FBG compared to $3(3.2 \%)$ for underweight women; 33 $(10 \%)$ for overweight women and $42(11.2 \%)$ for obese women. The prevalence of an elevated FBG in the morbidly obese was $11 / 70(15.7 \%)$. In a multivariate analysis, there was a significant association between the overweight BMI group and FBG, OR 2.02 [CI $1.08-3.79$ ], $\mathrm{p}=0.028$; obese BMI OR 1.94 [CI $1.04-3.62$ ], $\mathrm{p}=0.037$; and morbidly obese BMI OR 2.89 [CI $1.25-6.78$ ], $\mathrm{p}=0.013$ when compared to the normal weight group.

\section{Lipid panel}

The results of the lipid panel measurements are available for 972 women. Total cholesterol (TC) was elevated in 246 (25.3\%), high-density lipoprotein (HDL) was lower than normal $(<1.26 \mathrm{mmol} / \mathrm{l})$ in 574 $(59.1 \%)$ and low-density lipoprotein (LDL) was elevated in $147(15.1 \%)$. The serum triglyceride level was elevated in only $51(5.2 \%)$ of all women tested. There was no significant association with obesity defined by BMI and an abnormal TC. A lower than normal HDL was significantly associated with obesity measured by BMI, OR 1.59 CI [1.20 $2.10], \mathrm{p}=0.001$. Most obese women $(176 / 333,52.9 \%)$ had a normal TC and a low HDL.

The LDL was elevated in $49 / 140$ (35\%) for obese women compared to $91 / 140$ (65.0\%) for nonobese women, $\mathrm{p}=\mathrm{NS}$. The TC to HDL ratio was calculated for 983 women. The mean TC/HDL ratio for obese women was $4.08 \pm 1.78$ compared to $3.78 \pm$ 1.69 for non-obese women, $\mathrm{p}=0.003$. Overall, $42 \overline{5}$ $(47.4 \%)$ obese women had an optimal ratio less than
$3.5: 1 ; 288(32.1 \%)$ had a ratio between $3.5: 1$ and 4.9:1; and $184(20.5 \%)$ had an abnormal ratio $\geq 5.0: 1$. There was a significant association with increased TC/HDL ratio $\geq 5.0$ and obesity, OR 1.11 CI [1.02$1.20], \mathrm{p}=0.013$. There was a marginally significant association with obesity measured by BMI and triglyceride level, $\mathrm{p}=0.049$, with $24 / 333(7.2 \%)$ of obese women and 25/599 (4.2\%) of non-obese women being detected with hypertriglyceridemia.

\section{Discussion}

The Women's Health Study of Accra is the first comprehensive assessment of urban women's health in a West African nation. The risk factors for obesity include increasing age to 69 years, the number of full term pregnancies and age at last delivery. Every submetropolitan district in this study of Ghanaian women, whether affluent or not, had at least a 30\% obesity rate. The prevalence rate in this study is similar to that reported for the USA [8].

The WHSA identified a prevalence of obesity that is higher than earlier reported studies on Ghanaian women in Accra. In one previous study, the reported mean BMI of urban women was 22.6 $\mathrm{kg} / \mathrm{m}^{2}$ compared to a mean BMI of $27.9 \mathrm{~kg} / \mathrm{m}^{2}$ from the WHSA [9]. While the WHSA identified no significant association with measures of affluence such as income, occupation or education level, the previous report stated that those with the highest BMI's were from the highest income residential areas.

The Transition and Health during Urbanization of South Africans (THUSA) study revealed that BMI, Waist to Hip Ratio [10] and Waist Circumference [11] as measures of obesity are correlated with hypertension, elevated serum triglycerides, fasting glucose and log fasting insulin [12]. They also report a significant negative correlation with HDL and obesity, as shown in the WHSA, and reported that 
waist circumference was the greatest predictor of non-communicable disease in black Africans.

In the WHSA, BMI was not significantly associated with an increase in total cholesterol. This is consistent with reports indicating that fat distribution as measured by the waist to hip ratio affects cholesterol levels more than body mass index [13]. Other studies have shown that hypercholesteremia was significantly associated with an obese BMI [14].

Serum triglycerides were not significantly associated with an obese BMI in the WHSA. Previous studies have shown strong correlations between BMI and triglycerides that was not identified in this Ghanaian population $[15,16]$. Most of the obese women had a lower than normal level of HDL, the favorable lipoprotein that when elevated confers cardiac protection [17]. The TC/HDL ratio $(\geq 5.0: 1)$ was significantly higher in obese women. This, too, is a concern, as this ratio is a powerful predictor of cardiovascular risk [18]. The Nurses' Health Study found that the risk of developing type 2 diabetes increases as BMI increases $[19,20]$. In a prospective study representative of the U.S. population, 27 percent of new cases of diabetes were attributable to weight gain of $5 \mathrm{~kg}(11 \mathrm{lb})$ or more in adulthood [21].

\section{Conclusion}

We have shown that overweight and obesity is a common condition in adult women in Accra, Ghana and that a BMI in the obese range is significantly linked to major health illnesses in this population. The officials in the ministry of health of developing countries as well as the physicians and the lay population must recognize the increasing prevalence of chronic illnesses such as obesity, hypertension and diabetes in their adult population. Counseling to avoid the weight gain seen with increasing age should be started when women are quite young. Encouragement to reduce caloric intake of high fat foods and the need to increase physical exercise should be started in grade school. Few obese women live to an elderly age.

\section{Acknowledgements/Funding:}

The World Health Organization, United States International Development Agency and Fulbright New Century Scholar Program (AGH) provided funding.

\section{References}

1. World Health Organization. Obesity and overweight. Fact Sheet. 2004; www.who.org $\backslash$ Papers $\backslash$ Obesity $\backslash$ WHO Obesity and overweight.htm.
2. McLellan F. Obesity rising to alarming levels around the world. Lancet. 2002; 359(9315): 1412 .

3. Walker AR, Adam F, Walker BF. World pandemic of obesity: the situation in Southern African populations. Public Health. 2001; 115 368-372.

4. McGranahan, G and J Songsore. Wealth, health and the urban household: weighing environmental burdens in Accra, Jakarta and Sao Paulo. Environment 1994; 36:4-11 and 40-45.

5. Megill, D. Recommendations For designing master sample for Ghana intercensal household survey program, Demographic and Socioeconomic Research Services, International Programs Center, Ghana, US Bureau of the Census. Washington D.C. 2002.

http://www.census.gov/ipv/www/idb/countr y/ghportal.html

6. Norton K, Whittingham NO, Carter L Kerr D, Gore C, Marfell-Jones M. Chapter 2: Measurements techniques in anthropometry, In Norton K, Olds I. Anthropometrica. A textbook of body measurement and health courses. Sydney: University of New South Wales press, 1996. pp. 25-75.

7. World Health Organization. Obesity: Preventing and managing the global epidemic. Report of a WHO Consultation of obesity. Geneva, World Health Organization, 1998. www.who.org/int.

8. Hedley AA, Ogden CL, Johnson CL, Carroll MD, Curtin LR, Flegal KM. Prevalence of overweight and obesity among US children, adolescents, and adults, 1999-2002. Journal of the American Medical Association. 2004; 291:2847-2850.

9. Amoah AG. Sociodemographic variations in obesity in among Ghanaian adults. Public Health Nutrition. 2003; 6:751-757.

10. Albu JB, Murphy L, Frager DH, Johnson JA, Pi-Sunyer FX. Visceral fat and racedependent health risks in obese nondiabetic premenopausal women. Diabetes. 1997; 46: 456-462.

11. Dupres JP, Nadeau A. Tremblay A, Role of deep abdominal fat in the association between regional adipose tissue distribution and glucose tolerance in obese women. Diabetes. 1989; 38:304-309.

12. Kruger HS, Venter CS, Vorster HH. Obesity in African women in the North West Province, South Africa is associated with an increased risk of non-communicable 
diseases: the THUSA study. Transition and Health during Urbanization of South Africans. British Journal of Nutrition. 2001; 86:733-740.

13. Reeder BA, Angel A, Ledoux M, Rabkin SW, Young TK, Sweet LE. Obesity and its relation to cardiovascular disease risk factors in Canadian adults. Canadian Heart Health Surveys Research Group. Canadian Medical Association Journal. 1992; 146:2009-2019.

14. Manson JE, Colditz GA, Stampfer MJ, A prospective study of obesity and risk of coronary heart disease in women. New England Journal of Medicine. 1990; 322:882-889.

15. Denke MA, Sempos CT, Grundy SM. Excess body weight. An underrecognized contributor to dyslipidemia in white American women. Archives of Internal Medicine. 1994; 154:401-410.

16. Mann JI, Lewis B, Shepherd J. Blood lipid concentrations and other cardiovascular risk factors: distribution, prevalence, and detection in Britain. British Medical Journal. 1998; 296:1702-1706.

17. Assman G and Gotto AM. HDL cholesterol and protective factors in atherosclerosis. Circulation. 2004; 109 (23 Supp 1):iii 8-14.

18. Scranton R, Sesso HD, Stampfer MJ, Levenson JW, Buring JE, Gaziano JM. Predictors of 14-year changes in the total cholesterol to high-density lipoprotein cholesterol in men. American Heart Journal. 2004; 147: 1033-1038.

19. Colditz GA, Willett WC, Stampfer MJ, et al. Weight as a risk factor for clinical diabetes in women. American Journal of Epidemiology. 1990; 132:501-513.

20. Colditz GA, Willett WC, Rotnitzky A, Manson JE. Weight gain as a risk factor for clinical diabetes mellitus in women. Annals of Internal Medicine. 1995; 122:481-486.

21. Ford ES, Williamson DF, Liu S. Weight change and diabetes incidence: findings from a national cohort of US adults. American Journal of Epidemiology. 1997; 146:214-222. 